University of Warwick institutional repository: http://go.warwick.ac.uk/wrap This paper is made available online in accordance with publisher policies. Please scroll down to view the document itself. Please refer to the repository record for this item and our policy information available from the repository home page for further information.

To see the final version of this paper please visit the publisher's website. Access to the published version may require a subscription.

Author(s): Ilias Livanos

Article Title: Modelling the Incidence of Unemployment: The Case of Greece

Year of publication: Forthcoming

Link to published version:

http://www.tandf.co.uk/journals/titles/13504851.asp

Publisher statement: None 


\title{
Modelling the incidence of unemployment: the case of Greece
}

\author{
Dr. Ilias Livanos, \\ Institute for Employment Research- University of Warwick, \\ Coventry, CV4 7AL, UK, \\ I.Livanos@warwick.ac.uk \\ JEL Classification: J60, J64 \\ Keywords: Unemployment; Logit model; Greece
}

\begin{abstract}
In this paper, micro-data from the 2004 Labour Force Survey is used to model the incidence of unemployment in Greece and assess whether personal attributes of the individual, such as educational level, affect the probability of being unemployed. For that purpose, a logit regression model was constructed. It was found that the type of qualification ( $\mathrm{PhD}$, Masters, University degree, etc.) that an individual holds does not affect the probability of being unemployed. However, the incidence of unemployment is found to be affected by the subject studied. Other attributes of the individuals that were found to affect the probability of unemployment are: gender, marital status, and region of residence.
\end{abstract}




\section{Introduction}

Previous studies on unemployment in Greece have identified a high degree of unemployment persistence (Miaouli 1993, Demekas and Kontolemis 1996, Katsimi 2000). However, there is a gap in the literature about the factors that determine the occurrence of unemployment at the micro-level. In trying to explain the incidence of unemployment, this paper uses a logit model estimated by using data taken from the Labour Force Survey (LFS). The probability of an individual being unemployed is regressed on a number of factors such as sex, age group, level of qualification, subject studied, marital status, and region of residence.

\section{Levels of Unemployment}

One of the most striking features of the Greek labour market is the high rate of unemployment among people with higher degrees. In particular, individuals holding both University and Technical University degrees experience high levels of unemployment. To illustrate, in 2004 (see Table 1), the rates of unemployment for individuals from these groups were as high as that of those with primary education only $(8 \%)$. Nevertheless, the levels of unemployment vary across different subjects areas. For instance, for some subject groups, such as Agriculture, the level of unemployment is very high (18\%) while for some others, such as Engineering, is relatively low (8\%).

Moreover, other groups that experience high levels of unemployment are: young people, particularly new entrants to the labour market, and females. Unemployment is also particularly high among young people, and especially 
among new entrants in the labour market, as well as among females. As for the different age-groups, unemployment is much higher for young people, while it decreases as the age increases. As for the latter, the percentage of unemployment for females $(16 \%)$ is more than twice as high as for males $(6 \%)$.

In addition, unemployment varies considerably across the regions. In particular, Northern parts of Greece (Eastern, Western and Central Macedonia) have higher rates of unemployment $(13 \%, 16 \%, 12 \%$ respectively) than Southern parts (Athens, Attica, Crete with 11\%, 9\% and 6\% respectively).

\section{Data used and econometric methodology.}

The analysis draws on micro data from the Greek Labour Force Survey for the second (spring) quarter of 2004. The sample of the survey is 30.000 households and includes 80.000 observations approximately. The econometric methodology used in this paper is similar to the one used by Livanos (forthcoming; 2007) for modeling the incidence of long-term unemployment and self-employment. In particular, the probability of an individual being unemployed is regressed on a number of attributes of the individual. The econometric specification is expressed as follows:

$\operatorname{Ln}\left[P_{i} /\left(1-P_{i}\right)\right]=\alpha+X_{i 1} \beta_{1}+X_{i 2} \beta_{2}+X_{i 3} \beta_{3}+X_{i 4} \beta_{4}+X_{i 5} \beta_{5}+X_{i 6} \beta_{6}+X_{i 7} \beta_{7}+$ $\varepsilon_{\mathrm{i}}(1)$

where Pi denotes the probability that individual $\mathrm{i}$ is unemployed, $\mathrm{X}_{\mathrm{i} 1}$ denotes gender, $\mathrm{X}_{\mathrm{i} 2}$ denotes marital status, $\mathrm{X}_{\mathrm{i} 3}$ denotes level of qualification, $\mathrm{X}_{\mathrm{i} 4}$ denotes 
region, $\mathrm{X}_{\mathrm{i} 5}$ denotes subject studied, $\mathrm{X}_{\mathrm{i} 6}$ denotes the age group, and $\mathrm{X}_{\mathrm{i} 7}$ denotes the year of graduation.

\section{Empirical results}

The results of the econometric analysis are reported in Table 2. The coefficients are computed using the 'maximum likelihood estimation' (MLE). The model chi-square suggests that the model is statistically significant (chi2 $=0.000$ ) and the results of the model are quite robust as many of the coefficients are significant at the $1 \%$ level.

The odds ratio is presented in column 1 of Table 2 . An odds ratio above 1.0 means that the odds of being unemployed for a given category are greater than for the reference category and similarly an odds ratio below 1.0 means that the odds of being unemployed for a given category are less than the reference category. The closer the odds ratio is to 1.0 , the more independent is the dependent variable of the explanatory variables.

Starting with gender, the odds of a female individual being unemployed is 2.88 times greater than the odds of a male individual. This finding highlights one of the most important issues of the Greek labour market, the high level of unemployment amongst females, which is one of the highest in the European Union $^{1}$.

Moreover, the probability of being unemployed changes according to someone's marital status. Married individuals have lower probabilities of being 
unemployed than single individuals. In particular, for a single individual the odds of being unemployed is 1.5 times greater than that of a married individual, which is set as the reference category. In addition, divorced individuals have higher odds (1.3) of being unemployed than married ones. The above finding can probably be explained by the fact that married individuals have usually more responsibilities (children etc.) than non-married and therefore have stronger incentives to find employment.

Turning to the educational attainment of the individual it is found that the level of qualification does not have an impact on the probability of the individual being unemployed. In particular, no statistically significant relationships were found when comparing the unemployment probability of university degree holders with other levels of qualification such as $\mathrm{PhD}$, Masters, Technological University and Other Qualifications. However, a statistically significant relationship was found when comparing University degree holders with individuals with no qualification. In that case, the odds of an individual with no qualification being unemployed was found to be 1.2 times greater than the odds of someone holding a University degree. The above finding is also supported by evidence (Livanos, 2007), which suggest that the level of one's degree does not affect the odds of being short or long-term unemployed. This could be explained by the general focus of individuals, their families and the education providers, on higher education, during the last two decades, which has created an excess supply of graduates (with various levels of qualifications). A result of the plethora of graduates is that they end up having similar probabilities of being in employment or unemployment irrespective of their level of qualification. 
On the other hand, it was found that the subject an individual has studied affects his/her odds of being unemployed. The reference category for subject studied is Humanities and Arts, which has a particularly high level of unemployment. Individuals who have studied subjects related to Medical Studies and Services have particularly lower odds (0.67 each) of being unemployed than individuals who have studied Humanities and Arts. Sociology, Economics and Law as well as Engineering, Constructions and Industry are also subject areas where the probabilities of being unemployed are lower than Humanities and Arts. Particularly interesting is the fact that even individuals who have only basic education, and have studied general courses such as literacy, numeracy, and development of personal skills (which is the lowest level of qualification) have lower odds of being unemployed than individuals studied Humanities and Arts, which are subjects that include various levels of qualification such as a University degree and a Technical University degree. The above finding could be attributed to the nature of the Greek higher educational system, which keeps producing graduates whose subject areas, such as Humanities and Arts, do not respond to the needs of the labour market. As a result, individuals of these disciplines face low probabilities of employment.

The area of residence is another factor that affects the odds of being unemployed. The reference category for the region of residence is set as Athens. The residents of most of the other regions have a higher probability of being unemployed than the residents of Athens, where most of the economic activity in Greece is concentrated. The regions of Macedonia (Eastern, Central and Western) have particularly higher probability of being unemployed when 
compared to Athens $(1.5,1.5$, and 2.4 respectively). Residents of Sterea Ellada and Western Greece have also particularly greater odds of being unemployed than those of Athens. The only region whose residents have lower odds of being unemployed compared to Athens is Crete (0.7), which is a rather agricultural area served by, predominantly, small family businesses and therefore has a low level of unemployment.

Turning to the age group of the individual, it was found that age does not determine the odds of unemployment. Reference category was set as the age group 35-44. The only group whose coefficient is statistically significant is the 15-24 age group, which has 1.7 times greater odds of being unemployed than the age group 35-44. This fact can be explained partly by the high legal protection of the already employed and partly by the lack of experience of individuals of early age.

Finally, it was found that the year of graduation slightly affects the probability of being unemployed. In particular, if the year of graduation increases by one, meaning if it becomes more recent by one year, then the odds of being unemployed increase by only 1.02 times.

\section{Conclusion}

In this paper, a logit model was estimated for the incidence of unemployment in Greece using LFS data. It was found that the level of qualification does not affect the incidence of unemployment apart from individuals with no qualifications, who have higher odds of being unemployed than University degree holders. On the other hand, the subject that an individual has studied was 
found to affect the probability of being unemployed. In addition, the occurrence of unemployment depends on various attributes of an individual such as gender, marital status and region of residence. In particular, females, single individuals, and residents of regions outside Athens have a higher probability of being unemployed than the reference categories, males, married and residents of Athens respectively. The age of an individual was also found to affect the incidence of unemployment, but only to a certain extent.

\section{Acknowledgements}

The author is grateful to Cagri Yalkin for her valuable contribution to this paper.

\section{Footnote}

1 In 2004, the average rate of female unemployment in EU(15) was $9.3 \%$ and in Greece 16\% (Employment in Europe 2005). 


\section{References}

Demekas, D. and Z. Kontolemis. (1996) Unemployment in Greece - A Survey of the Issues, IMF Working Paper no. 91.

Katsimi, M. (2000) "Stochastic shifts in the natural rate of unemployment: evidence from Greece”, Applied Economic Letters, 2000, 7, pp. 239-242.

Livanos, I. (forthcoming) What determined self-employment? A comparative study, Applied Economic Letters.

Livanos, I. (2007) The incidence of long-term unemployment: evidence from Greece, Applied Economic Letters, 14, pp. 405-408.

Miaouli, N. (1998) "Employment persistence and wage settings in the Greek labour market”, Journal of Economic Studies, 25, 2, pp. 98--11. 
Table 1 Unemployment in Greece, 2004

\begin{tabular}{|c|c|}
\hline & Unemployment (\%) \\
\hline \multicolumn{2}{|l|}{ Type of qualification } \\
\hline $\mathrm{PhD}$ & 3 \\
\hline Masters & 7 \\
\hline University Degrees & 8 \\
\hline Technical University Degrees & 8 \\
\hline Vocational Qualifications & 14 \\
\hline Secondary Education & 12 \\
\hline Primary Education & 8 \\
\hline \multicolumn{2}{|l|}{ Subject Studied } \\
\hline General Courses & 10 \\
\hline Educational Studies & 11 \\
\hline Humanities and Arts & 12 \\
\hline Sociology, Economics and Law & 13 \\
\hline Physics, Maths and Computers & 15 \\
\hline \multicolumn{2}{|l|}{ Engineering, Constructions } \\
\hline And Industry & 8 \\
\hline Agriculture and Vet Studies & 16 \\
\hline Medical Studies & 11 \\
\hline Services & 11 \\
\hline \multicolumn{2}{|l|}{ Sex } \\
\hline Males & 6 \\
\hline Females & 16 \\
\hline \multicolumn{2}{|l|}{ Age group } \\
\hline $15-24$ & 26 \\
\hline $25-34$ & 13 \\
\hline $35-44$ & 8 \\
\hline $45-54$ & 5 \\
\hline $55+$ & 4 \\
\hline \multicolumn{2}{|l|}{ Region } \\
\hline Eastern Macedonia & 13 \\
\hline Central Macedonia & 12 \\
\hline Western Macedonia & 16 \\
\hline Ipeiros & 12 \\
\hline Thessaly & 10 \\
\hline Ionian Islands & 10 \\
\hline Western Greece & 12 \\
\hline Sterea Ellada & 8 \\
\hline Rest of Attica & 9 \\
\hline Peloponnesus & 9 \\
\hline North Aegean & 9 \\
\hline South Aegean & 6 \\
\hline Crete & 9 \\
\hline Athens & 11 \\
\hline Thessalonica & 10 \\
\hline Total & 10 \\
\hline
\end{tabular}

Source: Processed LFS Data 2004 (2nd term) 
Table 2 Logit regression results, 2004 Greek LFS data $\left(2^{\text {nd }}\right.$ quarter)

(1)

(2)

Explanatory variables

Odd Ratios $^{\#} \quad$ z-ratios

\begin{tabular}{|c|c|c|c|}
\hline \multirow[t]{2}{*}{ Gender } & Female & 2.88 & $(28.28)^{* * *}$ \\
\hline & Male & $\S$ & \\
\hline \multirow[t]{4}{*}{ Marital Status } & Single & 1.53 & $(9.19) * * *$ \\
\hline & Married & $\S$ & \\
\hline & Widow & 1.04 & $(0.28)$ \\
\hline & Divorced & 1.33 & $(3.03)^{* * *}$ \\
\hline \multirow[t]{6}{*}{ Level of Qualification } & $\mathrm{PhD}$ & 1.27 & $(0.88)$ \\
\hline & Masters & .99 & $(-0.04)$ \\
\hline & University Degrees & $\S$ & \\
\hline & Tech. University Degree & .84 & $(-1.40)$ \\
\hline & Other Qualifications & 1.09 & $(1.22)$ \\
\hline & No Qualifications & 1.22 & $(2.67) * * *$ \\
\hline \multirow[t]{15}{*}{ Region } & Eastern Macedonia & 1.50 & $(5.39) * * *$ \\
\hline & Central Macedonia & 1.55 & $(5.60) * * *$ \\
\hline & Western Macedonia & 2.40 & $(9.58) * * *$ \\
\hline & Ipeiros & 1.36 & $(4.14)^{* * *}$ \\
\hline & Thessaly & 1.29 & $(3.20)^{* * *}$ \\
\hline & Ionian Islands & 1.25 & $(1.85)$ \\
\hline & Western Greece & 1.37 & $(4.06)^{* * *}$ \\
\hline & Sterea Ellada & 1.54 & $(5.47) * * *$ \\
\hline & Rest of Attica & .95 & $(-0.60)$ \\
\hline & Peloponnisos & 1.07 & $(0.88)$ \\
\hline & North Aegean & 1.21 & $(1.58)$ \\
\hline & South Aegean & 1.04 & $(0.41)$ \\
\hline & Crete & .70 & $(-4.20) * * *$ \\
\hline & Athens & $\S$ & \\
\hline & Thessalonica & 1.17 & $(2.40)^{* *}$ \\
\hline \multirow[t]{9}{*}{ Subject Studied } & General Courses & .73 & $(-323) * * *$ \\
\hline & Educational Studies & 1.09 & $(0.69)$ \\
\hline & Humanities and Arts & $\S$ & \\
\hline & Sociology, Economics and Law & .69 & $(-3.80)^{* * *}$ \\
\hline & Physics, Maths and Computers & .77 & $(-0.73)$ \\
\hline & Engineering, Constructions and Industry & .70 & $(-3.31)^{* * *}$ \\
\hline & Agriculture and Vet Studies & 1.06 & $(0.38)$ \\
\hline & Medical Studies & .67 & $(-3.49) * * *$ \\
\hline & Services & .67 & $(-3.35) * * *$ \\
\hline \multirow[t]{5}{*}{ Age Group } & $15-24$ & 1.72 & $(5.92)^{* * *}$ \\
\hline & $25-34$ & 1.08 & $(1.23)$ \\
\hline & $35-44$ & $\S$ & \\
\hline & $45-54$ & .89 & $(-1.64)$ \\
\hline & $55+$ & 1.00 & $(0.06)$ \\
\hline Year of Graduation & & 1.02 & $(5.13) * * *$ \\
\hline
\end{tabular}

